\title{
Geographic variation in floral traits is associated with environmental and genetic differences among populations of the mixed mating species Collinsia heterophylla (Plantaginaceae)
}

\begin{tabular}{|r|l|}
\hline Journal: & Botany \\
\hline Manuscript ID & cjb-2016-0014.R3 \\
\hline Manuscript Type: & Article \\
\hline Complete List of Authors: & $\begin{array}{l}\text { Lankinen, Åsa; Sveriges landbruksuniversitet Alnarp } \\
\text { Madjidian, Josefin; Lunds Universitet } \\
\text { Andersson, Stefan; Lunds Universitet }\end{array}$ \\
\hline Keyword: & $\begin{array}{l}\text { Climate, genetic correlation, heritability, mating system evolution, } \\
\text { phenotypic plasticity }\end{array}$ \\
\hline \multicolumn{2}{|c}{} \\
\hline
\end{tabular}




\section{Geographic variation in floral traits is associated with}

\section{environmental and genetic differences among populations of the mixed mating species Collinsia heterophylla (Plantaginaceae)}

Åsa Lankinen ${ }^{1,2^{*}}$, Josefin A. Madjidian² and Stefan Andersson ${ }^{2}$

${ }^{1}$ Swedish University of Agricultural Sciences, Plant Protection Biology, P.O. Box 102, S-230

53 Alnarp, Sweden; ${ }^{2}$ Biodiversity, Department of Biology, Lund University, Ecology

Building, S-223 62 Lund, Sweden.

Email addresses of all authors: asa.lankinen@slu.se, josefinmadjidian@gmail.com, stefan.andersson@biol.lu.se.

*Present address: Swedish University of Agricultural Sciences, Plant Protection Biology, P.O. Box 102, S-230 53 Alnarp, Sweden.

Corresponding author; Åsa Lankinen, tel: +46 40 416735, e-mail: asa.lankinen@slu.se. 
Abstract: Relatively few studies have investigated how geography, environmental factors and genetics affect floral trait variation. We used mixed-mating Collinsia heterophylla to explore variation in a suite of floral traits related to mating system in populations representing four geographic regions of California, USA, and relate this variation to geography, climatic factors and local site characteristics. We evaluated the environmental vs. genetic trait variability in the greenhouse. Stage of anther-stigma contact correlated positively with temperature, stage of stigma receptivity was negatively associated with vegetation cover and flower size differed among populations without any clear relation to environmental factors. Greenhouse data indicated heritability for stage of anther-stigma contact, flower size and time to flowering, and positive correlations between field and greenhouse for stage of stigma receptivity and flower size; however, stage of antherstigma contact showed high degree of environmental influence. Stage of anther-stigma contact covaried positively with stage of stigma receptivity and flower size across maternal families, indicating genetic correlations between traits. In conclusion, phenotypic floral variation within mixed-mating $C$. heterophylla is mostly determined by a genetic component. Geography, environment and genetics affect traits differently, suggesting that ecological and evolutionary processes contribute to shaping variability in mating systemrelated traits.

Key words: Climate; genetic correlation; heritability; mating system evolution; phenotypic plasticity. 


\section{Introduction}

Genetic differentiation and speciation in plants is often associated with changes in mating system, for example, a shift from outcrossing to selfing (Stebbins 1950; 1974; Barrett et al. 1996; Slotte et al. 2013; Wright et al. 2013) which may be promoted by demographic and genetic benefits, including reproductive assurance and isolation from maladaptive gene flow (Levin 2010; Peterson and Kay 2014). In many hermaphrodite species the mating system is "mixed", i.e. seeds are produced via a combination of selfing and outcrossing (Goodwillie et al. 2005), either as a transient stage (Lande and Schemske 1985) or as a stable mating system (e.g., Lloyd 1979; Holsinger 1991; Porcher and Lande 2005; Harder et al. 2008; Johnston et al. 2009; Winn et al. 2011). The latter situation could occur when plants possess delayed selfing mechanisms to provide reproductive assurance under poor or temporally variable pollination conditions (Lloyd 1979; Kalisz et al. 2004; Eckert et al. 2006; Busch and Delph 2012).

Studying evolutionary predictors such as heritability and inter-trait correlations can contribute to our understanding of the underlying evolutionary causes of floral trait variation, particularly when population samples span a large portion of a species' range (Herrera et al. 2006; Etterson et al. 2016). Floral traits associated with mating system, e.g., flower size, flower colour, floral life-span and the degree of physical or temporal separation between male and female structures (herkogamy, dichogamy) (Runions and Geber 2000; Totland and Schulte-Herbrüggen 2003; Herlihy and Eckert 2007; Goodwillie et al. 2010; Button et al. 2012), are frequently influenced by multiple environmental factors acting as selective forces on genetic variation. Some environmental factors are likely to depend on the local habitat of the particular population, including the local pollinator community (Levin 1972; Pérez et al. 2013), competitors for pollination (Fishman and Wyatt 1999; Bell et al. 2005), floral antagonists (Strauss and Whittall 
2006) and vegetation cover (Fernández et al. 2012). Climate factors are acting at a larger spatial scale and can impose selection by affecting pollinator activity or outcrossing rate (Eckert et al. 2010; Thomann et al. 2013), or by influencing traits related to life-history (e.g., time to flower or longevity) (Amano et al. 2010; Elle et al. 2010; Ivey and Carr 2012). For example, stressful conditions can favour fast development of plants as a survival strategy (time-limitation hypothesis; Aarssen 2000), indirectly resulting in higher levels of selfing as a consequence of correlation between rate of plant development and developmental rates of mating-system traits (e.g., reduced herkogamy or dichogamy, Arroyo 1973; Mazer et al. 2004; Dudley et al. 2007). Even though previous studies of intraspecific variation have documented population divergence in a variety of traits related to mating system (Button et al. 2012; Dart et al. 2012), there is still a paucity of empirical data on the relative influence of genetics and environmental factors on floral trait variation related to mating system.

Variability in mating-system-related floral traits can result from phenotypic plasticity, the ability of a single genotype to change its phenotype in response to different environments (Schlichting and Pigliucci 1998). Because environmental factors and stress could influence costs related to selfing rate and timing of selfing (Fox and Reed 2011), phenotypic plasticity in mating-system traits may be adaptive. Spigler and Kalisz (2013) suggested that fluctuating environmental conditions could favour selection for phenotypic plasticity in mating-system traits, allowing plants to self more under temporarily harsh conditions, i.e. an extension of the time-limitation hypothesis (Aarssen 2000). Indeed, previous studies have confirmed that various abiotic factors, including nutrient, water and light condition, can modify matingsystem-related floral traits, e.g. flower size (e.g., Delesalle and Mazer 1996; Spigler and Kalisz 2013), anther-stigma distance (e.g., Vallejo-Martín and Barrett 2009) and floral longevity (e.g., Jorgensen and Arathi 2013). Independent of whether phenotypic plasticity in 
mating-system traits is adaptive or non-adaptive (van Kleunen and Fisher 2005), plasticity has potentially important effects on evolution of mating systems by affecting trait variation, opportunities for selection and the evolution of novel traits or trait combinations (Falconer and Mackay 1996; Schlichting and Pigliucci 1998; West-Eberhard 2005). In some cases, we may expect initially plastic responses to become genetically assimilated, as a result of selection favouring a particular trait expression under novel conditions (Price et al. 2003). For example, plasticity in selfing rate should enhance the ability to colonize harsh habitats by allowing reproductive assurance in the absence of pollinators. For subsequent establishment in a novel environment, we might, however, expect selection for constant high selfing rate to reduce maladaptive gene flow from populations adapted to other conditions (Levin 2010). To evaluate such hypotheses, it is necessary to study patterns of floral variation in at least two environments, e.g. field vs. greenhouse (Button et al. 2012; Dart et al. 2012; Bontrager and Angert 2015).

Additional contributors of floral trait variation are correlations between traits and whether existing correlations result from pleiotropy, linkage disequilibrium (caused by, for example, close physical linkage or correlational selection), or correlated plastic responses to the same environmental variable (Endler 1995; Armbruster and Schwaegerle 1996). Pleiotropic correlations are particularly interesting in this context, as they have the potential to influence short-term response to selection (Falconer and Mackay 1996) and constrain niche evolution (Wiens et al. 2010). Family-structured data from multiple populations could be useful for determining the underlying cause of trait associations.

Species within the genus Collinsia (Plantaginaceae) vary greatly in traits related to mating system. Two distinct groups can be recognized: i) intermediate to highly outcrossing (mixed mating) species with large flowers that show delayed selfing and delayed stigma receptivity; 
and ii) highly selfing species characterized by small flowers and early selfing and stigma receptivity (Armbruster et al. 2002; Randle et al. 2012; Kalisz et al. 2012). Delayed selfing, brought about by stigmas that contact the anthers late during floral development, allows for an initial period of outcrossing, in line with the reproductive assurance hypothesis (Lloyd 1979). Delayed stigma receptivity refers to the phenomenon that stigmas only support pollen germination and pollen tube growth after flowers have been open for a certain time period; thus Collinsia pollen that arrives to immature, unreceptive stigmas can only fertilize the ovules upon receptivity (Armbruster et al. 2002; Lankinen et al. 2007). Given the large floral variation observed at the genus level, studying floral variation at the species level provides an excellent opportunity to address questions about the importance of geography, environment and genetic variation across a species' range.

In the present study of $C$. heterophylla, which belongs to the mixed-mating group of Collinsia, we measured floral traits in a sample of Californian populations both in the field and the greenhouse to differentiate between genetic and environmental causes of variation. We related the variation among populations to geographical location (region vs. population within region), climate and habitat conditions, and performed correlation analyses to examine patterns of association among traits. Particular attention was given to traits related to mating system such as timing of stigma receptivity, timing of anther-stigma contact, flower size, corolla colour and floral phenology (the latter only measured in the greenhouse).

Specifically, we asked:

1) How is floral trait variation affected by geography and by ecological factors, as determined by climate and site characteristics?

2) How much of the observed variation in the floral traits has a genetic vs. environmental basis and which traits show heritable variation within populations? 
3) Do the floral traits covary at the within-population level and is the observed correlation structure similar to that observed at the between-species level (Kalisz et al. 2012)?

\section{Material and methods}

\section{Plant material and study populations}

Collinsia heterophylla Buist (Plantaginaceae) is a widely distributed diploid annual, native to the California Floristic Province (Newsom 1929; Neese 1993). Plants are common at sites below $1000 \mathrm{~m}$ a.s.l., typically growing on dry slopes in meadow-like environments shaded by trees.

Flowering occurs between March and June depending on latitude, elevation and site conditions. The flowers are arranged in whorls on long spikes. Each flower has four epipetalous stamens, a bicarpellate pistil with a single style, and a five-lobed corolla with one upper and one lower lip. Most corollas are white to pale purple on the upper lip and dark purple on the lower lip (Newsom 1929; Neese 1993). Prior work indicates that three anthocyanidins determine the flower colour and that the presence vs. absence of each anthocynidin is genetically determined (Garber 1958). Populations differ in the intensity of purple on the lower lip and some populations are polymorphic for presence/absence of dark pigment on the upper lip. In flowers with a dark upper lip, the pigment is often restricted to a distinct band, a trait determined by a single dominant gene (Weil and Allard 1964; Lankinen 2009). At flower opening, anthers are undehisced and the stigma is non-receptive. During flower development, the anthers usually dehisce one at a time over the course of 3-4 days, the style elongates and the stigma becomes receptive. After 1-3 days, the stigma contacts the dehisced anthers, and self-pollination can occur (see Armbruster et al. 2002 for a more detailed description). Because anthers dehisce over a period of several days (making self-pollen continuously available), there is opportunity to adjust timing of self- 
pollination in the absence of outcross pollen by altering timing of anther-stigma contact (Armbruster et al. 2002; Lankinen et al. 2007). The flowers develop into capsules (Newsom 1929; Neese 1993). Plants are self-compatible and pollinated by long-tongued, nectar-feeding bees (primarily species of Osmia, Bombus, Anthophora, and Habropoda) (Armbruster et al. 2002; Hersh et al. 2015). Mean population outcrossing rates range between 0.32 and 0.64 based on allozyme markers (4 populations, Charlesworth and Mayer, 1995) and microsatellite markers (5 populations, Kalisz et al. 2012), and between 0.62 and 0.94 based on morphological markers (2 sites within the same population, Weil and Allard 1964).

In 2008, between 29 April and 14 May, we sampled 27 populations in California (Table A1), of which 22 populations could be used for gathering floral trait data in the field (marked $\mathrm{F}$ in Table A1). Seeds for the greenhouse study were obtained from 20 populations (marked G), including 15 of those used in the field investigation (marked F, G). Our aim was to sample populations that covered the majority of the climatic and ecological variability encountered by the species. The sample range of our populations was $750 \mathrm{~km}$ and represents about two thirds of the north-south range of the species. Populations can be found both north and south of the sampling area, i.e. our outermost populations are relatively distant from the range limit. For practical reasons we sampled populations in four regions of the total study area (Fig. 1), where region was defined according to our sampling scheme. In the south, we sampled populations both south of Los Angeles in the Santa Ana Mountains (Riverside county, region 1) and north of Los Angeles in the Transverse Ranges and the Coast Ranges (Los Angeles, Ventura and Santa Barbara counties, region 2). Further north, we sampled populations in the Sierra Nevada Mountains (Mariposa and Madera counties, region 3) and the Coast Ranges around the Bay area (Santa Clara, Alameda and Napa counties, region 4). Region and population represent geographical effects varying at large and small scale, respectively. These large- and small- 
scale effects may or may not represent specific environmental variables such as climate and site characteristics (see below).

\section{Collection of field data}

To quantify geographic variation of floral phenotype, we measured eight traits in the field. Two traits, corolla colour and the presence/absence of dark pigment on the upper lip, were scored in all 22 populations that were flowering during our field work. To increase sample size for these two traits, we also included data collected in 2003 ( $\AA$. Lankinen, unpubl. data) from two early-flowering populations (203 and 204, Table A1). Timing of anther-stigma contact, timing of stigma receptivity (time to first sign of receptivity, termed partial receptivity, and full receptivity, respectively), and flower size (keel length, banner height and corolla tube length) were assessed in 13 populations (2-4 populations per region, Table A1). Plants had reached an advanced stage at the time of data collection (most plants had reached anthesis and some individuals had started to set seed). We aimed to include as many populations as possible, which limited the number of measurements made within populations.

\section{$\underline{\text { Measurements of floral traits }}$}

We assessed timing of anther-stigma contact by recording at which floral developmental stage the anthers and stigma first came into physical contact. Floral stages were defined as 0 4, reflecting the number of dehisced anthers (following Armbruster et al. 2002). We examined 10 flowers per floral developmental stage (i.e. a total $N$ of 50 ), each from a different individual, haphazardly chosen from the population, and determined whether anthers did or did not contact the stigma. When 10 flowers of a particular stage had been found, we disregarded flowers of that stage. We used logistic regression (Statistica 7.1, 2005) to estimate 
the stage at which $50 \%$ of all flowers had their anthers in direct contact with the stigma (see Armbruster et al. 2002). This measure, denoted "stage of anther-stigma contact" together with the corresponding logistic regression coefficient, quantifies when flowers in the population reached anther-stigma contact relative to flower opening.

To estimate stages of stigma receptivity we assessed stigmatic peroxidase activity at stage 0-4 by placing intact, pollen-free stigmas (checked by visual inspection under a magnifying glass) on a microscopic slide in a drop of $3 \%$ hydrogen peroxide and covering with a cover slip (Kearns and Inouye, 1993). Vigorous bubbling on the stigmatic surface within a few minutes has been observed to indicate full stigma receptivity (Lankinen et al. 2007). We examined 10 flowers per developmental stage (i.e. $N=50$ ), each from a separate individual, haphazardly chosen and usually excluding those scored for other traits. We determined (using logistic regression) the stage when $50 \%$ of all flowers showed full receptivity, denoted "stage of stigma receptivity" and used the logistic regression coefficient to estimate how quickly flowers in the population reached stigma receptivity. Because some pollen donors can germinate on partly receptive stigmas (Lankinen and Kiboi 2007), causing negative effects on maternal seed set in line with a sexual conflict over timing of stigma receptivity (Madjidian et al. 2012a), we were also interested in whether populations differ in how stigma receptivity progresses: rapid development from unreceptive to fully receptive stigmas (i.e., a short period of partial receptivity) could be beneficial if it prevents early pollen germination. Thus, we determined the stage when $50 \%$ of all flowers showed partial receptivity (as indicated by at least two small bubbles) and the corresponding logistic regression coefficient. In addition we used the difference between stage of full and partial receptivity (from the logistic regression estimates) as a measure of the rate with which flowers went from partial to full receptivity. 
We assessed flower size by measuring keel length, height of the upper lip (banner height) and corolla tube length (for details, see Fig. 1 in Armbruster et al. 2002). All three measurements were conducted on 10 flowers per population (all from different, haphazardly chosen individuals, usually not including those scored for other traits). Additionally, we determined corolla colour by scoring the base colour of corollas as light purple (nearly white), intermediate purple or dark purple. Even though some continuous colour variation exists, our populations were sufficiently uniform to fall into these three categories. Populations 19,181 and 182 had additional yellowish markings (see Garber 1958) but were categorized according to their base colour (light purple). In populations polymorphic for presence/absence of pigment on the upper lip, we estimated the proportion of plants with and without pigment (referred to as the dark- and white-lipped morph, respectively) by assessing all plants along one or a few transects laid out in each population (200-300 plants per population).

\section{$\underline{\text { Selection of floral traits for further analysis }}$}

To select the most informative and least redundant traits for further analyses we performed a principal component analysis (PCA) on population-level estimates of the 12 floral traits measured in the field study (13 populations). Based on the results of this analysis (Table A2), we selected stage of anther-stigma contact, stage of stigma receptivity, keel length and the second principal component (PC 2) in further analyses. To reduce the number of dependent variables for the analyses of the 13 populations, PC 2 was used as a proxy for the two positively correlated traits corolla colour and colour morph ratio (Spearman $r=0.770, N=22, P<$ 0.0001), hereafter referred to "combined flower colour". Corolla colour and colour morph ratio of all 24 populations were also used in complementary separate analyses (for details, see Analytical procedures). 


\section{Estimation of site characteristics}

A number of site characteristics were estimated to identify environmental determinants of between-population floral trait variation. We selected characteristics that were easy to record and considered to be of potential importance for plant performance. Population size was estimated by determining the number of flowering individuals, obtained by multiplying estimates of population area and plant density per $\mathrm{m}^{2}$. A soil sample was taken for measurement of $\mathrm{pH}$ (determined with a Lackmus test in a sample of soil shaken with distilled water). To estimate the level of competition experienced by the plants, we assessed the proportion of ground covered by vegetation (excluding $C$. heterophylla), averaged over the whole population by visually judging the horizontal cover repeatedly a few meters apart across the entire population.

\section{Collection of climate data}

To investigate how floral traits covary with climate factors, we used ArcGis 9.2 (Esri 2006) to estimate the average climate within $1 \mathrm{~km}$ of each population, based on data downloaded from "http://worldclim.org" (Hijmans et al. 2005). We selected two climatic variables of potential relevance for plant performance: annual mean temperature (BIO1) and mean diurnal range of temperature (mean of monthly [max-min temp], BIO2). Pollinator activity has been shown to be affected by temperature variation related to latitudinal or altitudinal differences (Arroyo et al. 1985; McCall and Primack 1992). Mean diurnal range of temperature was included because of previous observations that pollination frequency often is reduced in response to high temporal variability (cf. McCall and Primack 1992; Herrera 1995). 


\section{Collection of greenhouse data}

In spring 2011, we performed a large cultivation experiment to determine genetically-based variation within and between populations (Table A1). Plants from the field-collected seeds (collected per maternal family) were grown in pots with standard potting soil $\left(565 \mathrm{~cm}^{3}\right)$, placed in random positions across eight adjacent benches in a semi-automated, pollinator-free greenhouse at the Dept. of Biology, Lund University (Sweden). We used artificial light (14 h) to complement natural daylight in early spring, and an automated shade cloth system to prevent direct sunlight from reaching the plants. Greenhouse temperature varied between 20 and $30^{\circ} \mathrm{C}$, depending on outside weather condition. We watered plants as soon as the soil started to dry out to avoid any water stress. A total of 20 populations were used in the greenhouse study, including the five early-flowering populations not scored for floral traits in the field study (Table A1). To increase sample size in our field-greenhouse comparison, we compared greenhouse data from population 142 to field data collected from a closely adjacent population (pop 14, Table A1). We assume that, because of their close proximity $(<1 \mathrm{~km})$ and overlapping flowering time, these populations have the potential to exchange genes and share similar selection pressures. On average, each population was represented by $13.8 \pm 5.6$ (s.d.) maternal families (range $=5-27$ families), with 1-5 offspring per family and a total $N$ of 987.

Floral traits measured in the greenhouse were the same as in the field except that we also scored the greenhouse-grown plants for floral phenology (time to first flower from date of sowing, $n_{p o p}=20$, see Table A1). Corolla colour and presence/absence of dark pigment on the upper lip were assessed on each greenhouse-grown plant $\left(n_{p o p}=17\right)$. Estimates of stage of anther-stigma contact and stigma receptivity were based on data from two replicate flowers 
per developmental stage (1-4), i.e. a total of 8 flowers per plant. To prevent self-pollination and test for stigmatic receptivity we emasculated newly opened flowers (i.e. at stage $0=$ day 0) and used day 1-4 as a proxy for stage (Lankinen et al. 2007). For stage of anther-stigma contact and keel length, we obtained data from 1-2 plants per maternal family for on average 13.2 families per population (range $=5-15$ families/population, $n_{p o p}=13$, see Table A1). For stage of stigma receptivity we obtained data from one plant per maternal family for on average 9.6 families per population (range $=5-10$ families/population, $n_{p o p}=12$ ).

\section{Analytical procedures}

We used ArcGis 9.2 (Esri 2006) to visualise the geographic distribution of the floral trait variation. Statistical analyses were carried out with SPSS 20.0 (2011) unless otherwise stated.

To meet the assumption of normally distributed residuals in parametric analyses (general linear models, LMs, see below), we log-transformed population size, and arcsine-square-root transformed all traits measured as proportions. For corolla colour and colour morph ratio (the latter expressed as the proportion of the white- or dark-lipped morph), which had skewed distributions even after transformation, we used nonparametric methods or performed parametric analyses on principal component data (see results). Residuals of the familystructured data on start of flowering, stage of anther-stigma contact and keel length from the greenhouse experiment deviated from normality, but only slightly, and trait values showed low variation relative to the mean value; for these reasons, we followed the recommendation of Sokal and Rohlf (1995) to perform parametric analyses on these data. All LMs were based on Type-III sums of squares.

Floral trait variation in relation to geography, climate and site properties 
We investigated the effect of geography (region and population) on the floral traits stage of anther-stigma contact, stage of stigma receptivity, keel length, combined flower colour and greenhouse-estimated start of flowering using one-way or nested ANOVA. For field data we included the independent variable region (factor), and used population-level estimates as data points for the dependent variable (or when available, used individual data and added the random factor population nested within region to the model). For greenhouse data we tested the effects of the factors region (fixed), population (random; nested within region) and, when relevant, family (random; nested within population). When the effect of region was significant $(P<0.05)$ we performed a posthoc test to identify particular differences between regions (Tukey HSD). To test for regional differences of the 24 populations scored for corolla colour and colour morph ratio we performed separate non-parametric tests.

As a complementary approach, we tested for spatial distance effects by comparing the geographical distance matrix (derived from latitude and longitude data) with the trait distance matrix, based on all traits measured in the field as well as start of flowering measured in the greenhouse. A Mantel permutation procedure (9999 permutations), run in the ade4 package of R version 3.1.1 (R Development Core Team 2014), was used to determine whether corresponding elements in the two matrices were significantly correlated with each other (Pearson $r, P<0.05$ ). Following the detection of a significant correlation, we visualised the relationship in a variogram plot in the GeoR package. These analyses determined the potential for spatial autocorrelation effects to influence the analyses of trait-environment associations (see below). Controlling for spatial autocorrelation, i.e. the clustering of similar values across geographic scale, provides greater confidence when testing for relationships between traits and environmental variables. 
To evaluate the influence of climate and site characteristics on phenotypic floral trait variation, we used multiple linear regressions based on population means of the floral traits stage of anther-stigma contact, stage of stigma receptivity, keel length, combined flower colour and greenhouse-estimated start of flowering and the following predictor variables: annual mean temperature, mean diurnal range of temperature variation (climate factors), population size, soil $\mathrm{pH}$ and proportion ground cover (site characteristics). None of these predictor variables were strongly correlated to one another $(P>0.14)$. All variables were standardized by subtracting the cross-population mean and dividing by the cross-population standard deviation. Analyses were performed mainly on field-collected data as sample size was larger for this data set, except for start of flowering that was only measured in the greenhouse. For stage of anther-stigma contact, which differed between field and greenhouse conditions (see results), we performed additional regression analyses on greenhouse measurements as these data better reflect genetic differences among populations. Similar to the exclusion of nonsignificant covariates in other analyses (see above), we used a stepwise method to search for subsets of independent variables with high predictive value, based on a $P$-to-include value of 0.05 and a $P$-to-remove value of 0.10 . In the case of a significant region effect in the previously described analyses of variance (see above), we performed the multiple regression analysis on the standardized residuals from an ANOVA with regions as groups to exclude confounding effects of region. This approach is basically the same as controlling for region in ANCOVA, but has the advantage of providing direct estimates of the relationship between the dependent and independent variable (regression coefficient, $b$ ). Regression analyses on regionadjusted data were not strongly influenced by spatial autocorrelation, as evidenced by a nonsignificant relationship between standardized residuals and geographic distance between populations (see results). 
$\underline{\text { Genetic basis of floral trait variation }}$

We used the Pearson or Spearman correlation coefficient $(r)$ combined with paired t-tests or Wilcoxon signed-rank tests, based on population means or morph ratios to compare field and greenhouse estimates of measured traits for populations where we have both sets of data $(N=$ 11). A significant positive correlation between environments indicates a genetic basis for the divergence observed in the field.

The ANOVAs that tested for the effects of region and population in greenhouse-grown plants also provided data for the estimation of broad-sense heritability (termed $H^{2}$ ), calculated as the ratio of genetic variance $\left(V_{G}\right)$ to the total phenotypic variance within populations $\left(V_{P}\right)$, i.e. $H^{2}=V_{G} / V_{P}$. We used a minimum of two plants per maternal family (for sample sizes, see Table A1). We first calculated $V_{G}$ as 4 times the among-family variance under the assumption that progenies within families were related as half-sibs (each seed family was derived from several capsules per parent). To the extent that some progeny plants were related as full-sibs due to selfing or shared paternity, our initial $H^{2}$ estimates may include both additive and nonadditive genetic variation (Falconer and McKay 1996). As marker-gene data indicate appreciable levels of selfing in our study populations (range 22-74\%; M. Strandh, J. Jönsson, J.A. Madjidian, B. Hansson, Å. Lankinen, unpubl. data), we also obtained $H^{2}$ estimates adjusted for the observed range of selfing rates, using the method of Squillace (1974; see also Gauzere et al. 2013). Because our data were not fully balanced we also estimated $H^{2}$ from variance components derived from maximum likelihood analysis; however, the results were very similar and are thus not reported.

$\underline{\text { Genetic correlations within populations }}$ 
To test for genetic correlation between traits (Falconer and McKay 1996), we calculated family-mean correlations based on standardized residuals from ANOVAs using population as a categorical variable. This procedure provided correlation estimates adjusted for differences in the mean population phenotype.

\section{Results}

\section{Description of site characteristics}

The populations that flowered during our field work represented dry and more or less northfacing slopes at elevations between 162 and $846 \mathrm{~m}$ (mean \pm s.e., unless otherwise stated, $518 \pm 41.6, N=22$ ), commonly shaded by some trees. The flowering populations varied substantially in size, ranging from approximately 100 to $80000(7500 \pm 3700, N=21)$ individuals. Soils at the sample sites constituted a pH varying between 4.5 and 7 (5.4 \pm 0.17 , $N=15$ ). Plant communities were dominated by trees (mostly oaks), shrubs, ferns, grasses and herbs (e.g., Allium, Artemisia, Castilleja, Clarkia, Delphinium, Helianthus, Lupinus, Mimulus, Silene). The proportion of ground covered by vegetation ranged between 20 and $90 \%$ (63 \pm $5.2, N=18)$

Impact of geography, climate and site characteristics on phenotypic floral variation

Stage of anther-stigma contact estimated in the field was unaffected by region (Table 1, Fig. 1A). In contrast, stage of stigma receptivity differed between regions (Table 1). According to posthoc tests (Tukey) region 3 had earlier receptivity than the most southern region (region 1, mean difference \pm s.e.: $1.06 \pm 0.30, P=0.029$ ) (Fig. 1B). No other differences were significant, but there was a trend that region 1 showed later stigma receptivity than both region $2(P=$ 
$0.089)$ and region $4(P=0.068)$. Flower size, represented by keel length, was significantly influenced by variation among populations within rather than between regions (Table 1, Fig. 1C). Greenhouse data for stage of anther-stigma contact, stage of stigma receptivity, keel length and start of flowering all showed significant effects of population and, when tested, of family identity, whereas the regional influence failed to reach significance (Table 1). However, the effect of population was relatively weak for stage of stigma receptivity and there was a trend that this trait was influenced by region (Table 1).

Combined flower colour was significantly related to region (Table 1), largely because region 3 differed from regions 2 and 4 (Posthoc tests (Tukey); mean difference \pm s.e.: $2.19 \pm 0.40, P<$ 0.002 and $1.71 \pm 0.40, P=0.009$, respectively). Flowers in region 3 had high values because of their dark corollas (Fig. 1D) and high probability of having a pigmented upper lip. Region 2 also had higher values than region 1 (Posthoc tests (Tukey); mean difference \pm s.e.: $1.45 \pm 0.45$, $P<0.044)$. Similar effects of geography were obtained when corolla colour was analysed separately (see Fig. 1D) using non-parametric methods (data not shown). Separate analysis of the 24 populations from 2003 and 2008 that were scored as polymorphic for colour on the upper lip (Fig. 1E), revealed a clear effect of region: the dark-lipped morph was more common in northern regions ( 3 and 4$)$ than in southern regions $(1$ and 2$)\left(\chi^{2}=2565\right.$, d.f. $\left.=1, P<<0.0001\right)$. The dark-lipped morph was found in one out of seven populations in region 2, but in neither of the two populations in region 1 (Fig. 1E), resulting in a significant between-region difference for southern populations $\left(\chi^{2}=30.1\right.$, d.f. $\left.=1, P<0.0001\right)$. Dark-lipped flowers were significantly more common in region 3 than in region $4\left(\chi^{2}=1157\right.$, d.f. $\left.=1, P<<0.0001\right)$. However, there was also some variability in this trait within region 3 (Fig. 1E), even though all populations had dark flowers (Fig. 1D). 
Spatial autocorrelation was detected for field-estimates of stage of stigma receptivity (Mantel test; $r=0.341, P=0.017, N=13)$, but not for stage of anther-stigma contact $(r=0.089, P=$ 0.62), keel length $(r=-0.144, P=0.92)$, combined flower colour $(r=0.079, P=0.72)$ or greenhouse-estimates of flowering time $(r=-0.121, P=0.99, N=20)$. The variance of the difference in stage of stigma receptivity between populations increased linearly with the geographic distance between populations (not shown). This effect is in agreement with the effect of region detected for this trait; accordingly, analysis of region-adjusted residuals for stage of stigma receptivity could not detect any spatial autocorrelation $(r=-0.141, P=0.87)$. Multiple regression analyses involving climate factors (annual mean temperature, mean diurnal range of temperature) and site properties (population size, $\mathrm{pH}$ and proportion ground cover) showed that stage of anther-stigma contact was positively related to annual mean temperature (Fig. 2A). Using standardized residuals of stage of stigma receptivity to control for the effects of region, we found an association between early receptivity and high vegetation cover (Fig. 2B). Vegetation cover also correlated positively with standardized residuals for combined flower colour $(b=0.520 \pm 0.209$ (s.e.), d.f. $=11, P=0.030)$, implying that flowers are darker in denser vegetation. Keel length and flowering time in the greenhouse were unrelated to all climate and site characteristics (Multiple regression; $P>0.10$ ).

\section{Genetic basis and heritability of floral trait variation}

A direct comparison of trait values in the field and greenhouse showed strong positive correlations for population means of stage of stigma receptivity and keel length (Fig. 3B, C), suggesting a genetic influence on trait variation detected in the field. Nonetheless, greenhouse grown plants had larger keels (mean \pm s.e.: $18.0 \pm 0.304$ vs. $16.1 \pm 0.334 \mathrm{~mm}$, Paired t-test; $t=$ 10.2 , d.f. $=10, P<0.0001)$ and tended to have stigmas that became receptive slightly earlier in 
the greenhouse relative to the field $(2.80 \pm 0.122$ vs. $3.03 \pm 0.134)$, but the latter difference was only marginally significant (Paired t-test; $t=2.26$, d.f. $=9, P=0.051$ ). For stage of antherstigma contact, there was no significant association between field and greenhouse estimates (Fig. 3A). Moreover, the grand mean was significantly influenced by growing condition: anthers came in contact with the stigma more than half a stage later in the greenhouse than in the field $(3.15 \pm 0.088$ vs. $2.48 \pm 0.145$, Paired t-test; $t=5.55$, d.f. $=10, P=0.0002)$. This trait also showed a markedly reduced variance in the greenhouse $\left(s^{2}=0.074\right)$ relative to the field $\left(s^{2}=\right.$ 0.214) (Fig. 3A). In agreement with these results, population means for stage of anther-stigma contact measured in the greenhouse was unrelated to any of the climate and site variables measured (Multiple regression; $P>0.10$ ), as opposed to the results from the analysis of field data (Fig. 2A).

Corolla colour was consistent between growing conditions: each population received the same score in the greenhouse as it did in the field $(N=17$, comparison made for populations 203, 204 and those marked F and G in Table A1, see Fig. 1D). Likewise, the proportion of dark- and white-lipped plants in a population was highly correlated between growing conditions (Spearman $r=0.890, N=17, P<0.0001$ ). Morph ratios were not consistently higher or lower for plants grown in the greenhouse (Wilcoxon signed-ranks test, $P=0.17$ ).

Onset of flowering in the greenhouse was significantly later in the sample of 15 populations that flowered in the field in late April/early May than for the added sample of five earlierflowering populations $(21.4 \pm 1.30$ (s.e.) vs. $13.5 \pm 1.18$, t-test; $t=3.32$, d.f. $=18, P=0.0038)$.

Broad-sense heritability estimates $\left(H^{2}\right)$, i.e. the ratio of genetic variance to total phenotypic variance within populations, based on the half-sib assumption ranged from 0.74 for stage of anther-stigma contact and 0.86 for start of flowering to 1.08 (i.e. above the "permissible" range) for keel length. Heritabilities adjusted for marker-based estimates of selfing rate varied between 
0.33 and 0.79 (Table 2), indicating that some progeny were related as selfed full-sibs rather than half-sibs.

\section{Genetic correlations within populations}

The greenhouse data enabled us to estimate genetic correlations by comparing trait means for different progeny families. Analyses of standardized residuals (adjusted for differences between population means) showed that stage of anther-stigma contact was significantly positively associated with both stage of stigma receptivity and keel length (Table 3). We also detected a tendency for start of flowering to correlate positively with stage of anther-stigma contact and negatively with stage of stigma receptivity. Keel length was uncorrelated to both stage of stigma receptivity and start of flowering (Table 3).

\section{Discussion}

In our study of floral trait variation across populations of mixed-mating Collinsia heterophylla, the investigated traits differed in how they were linked to geography (region vs. population within region) and ecological factors (climate and local site characteristics). Stage of anther-stigma contact correlated positively with annual mean temperature (Fig. 1A, 3A), while stage of stigma receptivity was negatively associated with vegetation cover. Stage of stigma receptivity showed a regional pattern with earlier stigma receptivity in the Sierra Nevada Mountains compared to populations towards the southern coast (Fig. 1B, 3B). Flower size differed between populations but showed no regional variation (Fig. 1C). Moreover, stage of anther-stigma receptivity, flower size and time to flowering were heritable and most traits were significantly positively correlated between the field and greenhouse; however, stage of anther-stigma contact was strongly influenced by growing environment. Analyses 
using family-structured data from the greenhouse suggested that stage of anther-stigma contact was genetically correlated with stigma receptivity and flower size. While a genetic component appears to explain a large part of the floral variation, the relative influence of genetics and environment depended on the trait considered.

Influence of geography, climate and local site conditions on differences in floral phenotype

In Camissoniopsis cheiranthifolia, a species found on dunes along the Californian coast, three geographically distinct groups that differed in their degree of outcrossing and floral morphology were identified, although it was not clear which ecological factors generated this variation (Dart et al. 2012). Herbarium material of Clarkia pulchella showed low herkogamy in a climate with high spring and summer temperatures (Bontrager and Angert 2015), but the effects of local site conditions were not explored. In the present study of mixed-mating C. heterophylla, variation in stage of anther-stigma contact, i.e. timing of self-pollination, differed among populations rather than regions, and correlated positively to annual mean temperature (Fig. 2A). Later antherstigma contact in populations from warmer areas is in line with the prediction that pollinators are more frequent or active under such conditions (Lloyd 1979; Eckert et al. 2006; Busch and Delph 2012), which would reduce the need for early selfing. Several non-adaptive explanations are also possible, for example, that high temperatures may speed up development of floral tissue (Holtsford and Ellstrand 1992). To learn more about the causal effect of temperature on stage of anther-stigma contact it would be of great interest to perform more detailed studies of temperature and pollinator activity across populations.

Apart from an influence of climatic factors, floral traits can be affected by local ecological conditions, such as soil conditions or vegetation. In a study of the Mediterranean, bee-pollinated species Erysimum popovii, for example, pollen limitation was lower in populations with less 
rainfall and more bare soil (Fernández et al. 2012), a pattern that was attributed to differences in pollinator abundance as bees mainly nest underground in patches with low vegetation cover (Potts et al. 2005). In C. heterophylla, flower size (Fig. 1C) and time to flowering were most strongly influenced by population (considered to reflect local site conditions), while stage of stigma receptivity and traits related to flower colour were at least partly affected by regional factors. Flowers were particularly dark in the Sierra Nevada Mountains (region 3) (Fig. 1D), and stigmas had later receptivity in southern populations relative to populations in region 3 , but there was little differentiation among coastal populations (Fig. 1B). The regional difference in stage of stigma receptivity is corroborated by a previous greenhouse study of C. heterophylla which compared two populations from the Transverse Ranges (the southern part of region 2) with two populations from the Sierra Nevada Mountains (region 3) (Madjidian and Lankinen 2009). Both stigma receptivity and our measure of flower colour (combining corolla colour and morph ratio) were correlated with vegetation cover; stigma receptivity was later (Fig. 2B) and corollas lighter at sites with more bare soil. One possible adaptive explanation for this pattern is that vegetation cover affect pollinator abundance and the pattern of selection imposed by the pollinators (cf. Fernández et al. 2012). However, correlations do not prove causation and vegetation cover may be correlated to other factors, such as soil moisture, which was not measured in the current study. As no comparison to neutral genetic variation has been carried out (cf. Duncan and Rausher 2013), we cannot exclude non-selective forces such as random genetic drift in the present study system. To confirm that vegetation cover acts as a selective force on stigma receptivity and flower colour, future studies should explore how individual fitness covaries with the local pollinator community and other ecological factors that might be influenced by vegetation cover. 
Floral traits can be of varying importance for the mating system. Indeed, across Collinsia species timing of stigma receptivity correlated strongly with selfing rate, while other mating system-related traits, e.g. anther-stigma contact and corolla size, showed large variation within both the mixed-mating and selfing group of species (Kalisz et al. 2012). For example, corolla size may be driven by resource allocation costs (Teixido and Valladares 2013), floral antagonists (Strauss and Whittall 2006) or differences in the local pollinator community (Maad et al. 2013). One hypothesis explaining the different variation patterns found in $C$. heterophylla is that the investigated floral traits differ in how closely linked they are to the mating system and how much they are influenced by selection pressures unrelated to the mating system.

\section{Genetic vs. environmental influence on floral trait variation}

Floral traits generally show lower phenotypic plasticity than vegetative traits (e.g. Frazee and Marquis 1994; Brook and Weinig 2007) and traits of individual flowers are less plastic than plant-level floral traits, such as start of flowering and flower number (e.g. Caruso 2006; Van Etten and Brunet 2013). Our comparison of population means based on field and greenhouse data showed great consistency between growing conditions for start of flowering, stage of stigma receptivity, flower size, corolla colour and the proportion of dark- and whitelipped plants, suggesting that variation in these traits had a strong genetic component. In contrast, anther-stigma contact occurred considerably later and was less variable for flowers in the relatively more constant greenhouse environment and did not significantly correlate between the field and greenhouse estimates (even though the trend was in the expected direction). Thus, much of the observed variation in stage of anther-stigma contact must have been plasticity. Studies on other species suggest that herkogamy, i.e. anther-stigma separation, 
can be more plastic than other floral traits (e.g. Elle and Hare 2002; Mal and Lovett-Doust 2005; Brook and Weinig 2007). In two other species of Collinsia (C. parviflora and C. verna), plasticity was detected for timing of selfing, brought about by different timing of anther-stigma contact (Elle et al. 2010; Spigler and Kalisz 2013). Our present results for $C$. heterophylla adds to previous observations that traits related to anther-stigma separation or timing of anther-stigma contact tend to be more plastic than other floral traits.

An environmental influence on stage of anther-stigma contact in C. heterophylla casts doubt on an adaptive significance of the detected positive association between field-collected data for this trait and mean temperature (Fig. 2A). It is, however, possible that the ability to plastically adjust this floral trait, i.e. timing of selfing, to temperature is adaptive, provided this ability is genetically determined which is currently unknown. In our field study, we observed almost no pollinators in rainy and cold weather, but often recorded high pollinator activity under sunny conditions. During a sunny day with a temperature of $24^{\circ} \mathrm{C}$, as many as $87 \%( \pm 1.7 \%$ s.e $)$ of the plants received at least one visit (as determined by flourescent dye tracking; Å. Lankinen, J.A. Madjidian, unpubl. data). Interestingly, in C. heterophylla there was no significant effect of region on stage of anther-stigma contact, in accordance with our prediction that more plastic traits are less differentiated (cf. Price et al. 2003). Provided that stage of anther-stigma contact is a major determinant of outcrossing rate in C. heterophylla, there could be considerable potential for environmental variation to preserve the mixed mating system in a transitional stage (Eckert et al. 2009).

All traits studied for genetic variability within populations showed high broad-sense heritabilities ( $>0.70$, or 0.33 when adjusted for marker-based estimates of selfing rate), suggesting that these traits are regulated by genetic rather than environmental factors. We note that the "unadjusted" heritability of keel length $\left(H^{2}=1.08\right)$ exceeds the "permissible" 
range $(0-1)$, a result that can be attributed to sampling variability or possible violation of the (untested) assumption that progenies within families were related as halfsibs. When we relaxed the halfsib assumption and adjusted for selfing rate by multiplying the among-family variance by a smaller constant to yield $V_{G}$ (Squillace 1974), our heritability estimates were still substantial (0.33-0.48 for the highest selfing rate). It should be noted, however, that our study only used 2-5 progeny per maternal family, possibly reducing the precision of the heritability estimates; furthermore, we cannot exclude non-genetic influence such as maternal carry-over effects, which could have inflated the estimates. Broad-sense heritabilities tend to be larger than narrow-sense heritabilities (Falconer and McKay 1996) and may not reliably represent the genetic variation available to natural selection (Hansen et al. 2011). However, heritability in floral traits is often high (Ashman and Majetic 2006) and empirical data from studies of Mimulus guttatus (Kelly and Arathi 2003) and C. heterophylla (Lankinen et al. 2007; Madjidian et al. 2012b) confirm the presence of heritable variation in anther-stigma distance, timing of anther-stigma contact and stigma receptivity. These results, along with the strong genetic component of the floral traits investigated in $C$. heterophylla, indicate that these traits might respond to selection and thus contribute to the evolutionary potential of traits related to mating system (Baldwin et al. 2011; Hazzouri et al. 2013).

\section{Genetic correlations between floral traits}

Traits cannot respond independently to spatially varying selection when they are genetically associated as a result of pleiotropy, close physical linkage or correlational selection (Lande and Arnold 1983; Armbruster and Schwaegerle 1996). Our study was not designed to separate between processes generating trait covariance, but provided new data concerning the pattern of genetic correlations between floral traits at the within-population level. Our family-level 
analysis showed stage of anther-stigma contact to be positively genetically correlated with both stage of stigma receptivity and flower size, in agreement with previously detected correlations among species means (Kalisz et al. 2012). In contrast to patterns observed at the genus level, flower size was uncorrelated to stage of stigma receptivity. Interestingly, in Ipomoea hederacea covariance of floral traits show a latitudinal cline (Stock et al. 2014), suggesting that natural selection can cause divergence in floral covariance structure. Because the genetic correlations detected in $C$. heterophylla were weak $(r<0.22)$ and traits differed in their association with region vs. population (see Fig. 2), we consider pleiotropy and close physical linkage as less likely sources of covariance and instead hypothesize that selection has played a major role in shaping these patterns. In future studies, it would be of interest to study whether and how selection has contributed to the covariance between floral traits at both the within- and between-population level.

According to the time-limitation hypothesis it is favourable for plants to develop faster under harsh conditions (Aarssen 2000). Consistent with this hypothesis, previous results from C. parviflora showed that plants with early-maturing flowers had higher selfing ability, earlier stigma receptivity and anther dehiscence than those with late-maturing flowers (Elle et al. 2010). There may be a similar pattern in C. heterophylla, as we found a marginally significant $(P=0.059)$ positive correlation between stage of anther-stigma contact and start of flowering. However, further studies are needed to confirm this hypothesis.

\section{Conclusions}

In this study of $C$. heterophylla, floral trait variation known to influence mating system in the genus Collinsia (Armbruster et al. 2002; Kalisz et al. 2012) was mostly determined by a genetic component. We also found traits to be differentially affected by region, indicating that 
the combined effect of genetic and environmental factors varied among traits. Field data suggested that stage of anther-stigma contact covaries with temperature, whereas stage of stigma receptivity covaries with vegetation cover and differs between the inland and southern coastal populations. Greenhouse measurements showed a strong genetic basis for both traits, but also a difference in the relative impact of genetics and environmental factors, with stage of stigma receptivity being more consistent between environments than stage of anther-stigma contact. Moreover, there was significant within-population genetic variation in all traits examined, with patterns of correlation indicating links between early anther-stigma contact, early stigma receptivity and large flower size. The next step in the study of $C$. heterophylla is to investigate which of the measured traits are causally linked to the mating system. The traitspecific nature of divergence suggests an adaptive component of the floral trait variation within C. heterophylla (Endler 1977; Linhart and Grant 1996). However, to fully understand which evolutionary forces contribute to mating system variation in this and other study systems, it is important to determine the relative influence of drift vs. selection (Duncan and Rausher 2013) and to learn more about selection imposed by climate and local site conditions as well as the impact of pollinator-mediated selection on phenotypic plasticity.

\section{Acknowledgements}

The authors thank WS Armbruster, BG Baldwin, M Strandh and J Ågren for helpful discussions and comments on previous versions of the text. We are grateful that we could conduct part of the field work at Wantrup Preserve (Land Trust of Napa County). D. Gustavsson assisted in the field. This work was supported by the Swedish Research Council and Craaford Foundation to ÅL and by Anna och Svante Murbecks minnesfond and Battramska stiftelsen to JM. 


\section{References}

Aarssen, L.W. 2000. Why are most selfers annuals? A new hypothesis for the fitness benefit of selfing. Oikos 89: 606-612.

Amano, T., Smithers, R.J. Sparks, T.H. and Sutherland, W.J. 2010. A 250-year index of first flowering dates and its response to temperature changes. Proc. R. Soc. Lond. Biol. 277: $2451-2457$

Armbruster, W.S., and Schwaegerle, K.E. 1996. Causes of covariation of phenotypic traits among populations. J. Evol. Biol. 9: 261-276.

Armbruster, W.S., Mulder, C.P.H., Baldwin, B.G., Kalisz, S., Wessa, B., and Nute, H. 2002. Comparative analysis of late floral development and mating-system evolution in tribe Collinsiae (Scrophulariaceae S.L.). Am. J. Bot. 89: 37-49.

Arroyo, M.T.K. 1973. Chiasma frequency evidence on the evolution of autogamy in Limnanthes floccosa (Limnanthaceae). Evolution 27: 679-688.

Arroyo, M.T.K., Armesto, J.J., and Primack, R.B. 1985. Community studies in pollination ecology in the high temperature andes of central Chile II. Effect of temperature on visitation rates and pollination possibililies. Pl. Syst. Evol. 149: 187-203.

Ashman, T.L., and Majetic, C.J. 2006. Genetic constraints on floral evolution: a review and evaluation of patterns. Heredity 96: 343-352.

Baldwin, B.G., Kalisz, S., and Armbruster, W.S. 2011. Phylogenetic perspectives on diversification, biogeography, and floral evolution of Collinsia and Tonella (Plantaginaceae). Am. J. Bot. 98: 731-753.

Barrett, S.C.H., Harder, L.D., and Worley, A.C. 1996. The comparative biology of pollination and mating in flowering plants. Philos. Trans. R. Soc. London Biol. 351: 1271-1280. 
Bell, J.M., Karron, J.D., and Mitchell, R.J. 2005. Interspecific competition for pollination lowers seed production and outcrossing in Mimulus ringens. Ecology 86: 762-771.

Bontrager, M., and Angert, A.L. 2015. Effects of range-wide variation in climate and isolation on floral traits and reproductive output of Clarkia pulchella. Am. J. Bot. 103: 1-12.

Busch, J.W., and Delph, L.F. 2012. The relative importance of reproductive assurance and automatic selection as hypotheses for the evolution of self-fertilization. Ann. Bot. 109: 553562.

Button, L., Villalobos, A.L., Dart, S.R., and Eckert, C.G. 2012. Reduced petal size and color associated with transitions from outcrossing to selfing in Camissoniopsis cheiranthifolia (Onagraceae). Int. J. Plant Sci. 173: 251-260.

Caruso, C.M. 2006. Plasticity of inflorescence traits in Lobelia siphilitica (Lobeliaceae) in response to soil water availability. Am. J. Bot. 93: 531-538.

Charlesworth, D., and Mayer, S.S. 1995. Genetic variability of plant characters in the partial inbreeder Collinsia heterophylla (Scrophulariaceae). Am. J. Bot. 82: 112-120.

Dart, S.R., Samis, K.E., Austen, E., and Eckert, C.G. 2012. Broad geographic covariation between floral traits and the mating system in Camissoniopsis cheiranthifolia (Onagraceae): multiple stable mixed mating systems across the species' range. Ann. Bot. 109: 599-611.

Delesalle, V.A., and Mazer, S.J. 1996. Nutrient levels and salinity affect gender and floral traits in the autopgamous Spergularia marina. Int. J. Plant Sci. 157: 621-631.

de Witt, T.J., Sih, A., and Wilson, D.S. 1998. Costs and limits of phenotypic plasticity. Trends Ecol. Evol. 13: 1-8.

Dudley, L.S., Mazer, S.J., and Galusky, P. 2007. The joint evolution of mating system, floral traits, and life history in Clarkia (Onagraceae): genetic constraints vs. independent evolution. J. Evol. Biol. 20: 2200-2218. 
Duncan, T.M., and Rausher, M.D. 2013. Evolution of the selfing syndrome in Ipomoea. Front. Plant Sci. 4: 301.

Eckert, C.G., Samis, K.E., and Dart, S. 2006. Reproductive assurace and the evolution of uniparental reproduction in flowering plants. In Ecology and evolution of flowers. Edited by L.D. Harder, and S.C.H. Barrett. Oxford Univ. Press, Oxford, Great Britain. pp 183-203. Eckert, C.G., Ozimec, B., Herlihy, C.R., Griffin, C.A., and Routley, M.B. 2009. Floral morphology mediates temporal variation in the mating system of a self-compatible plant. Ecology 90: 1540-1548.

Eckert, C.G., Kalisz, S., Geber, M.A., Sargent, R., Elle, E., Cheptou, P.-O., Goodwillie, C., Johnston, M.O., Kelly, J.K., Moeller, D.A., Porcher, E., Ree, R.H., Vallejo-Marin, M., Winn, A.A. 2010. Plant mating systems in a changing world. Trends Ecol. Evol. 25: 35-43.

Elle, E., Gillespie, S., Guindre-Parker, S., and Parachnowitsch, A.L. 2010. Variation in the timing of autonomous selfing among populations that differ in flower size, time to reproductive maturity, and climate. Am. J. Bot. 97:.1894-1902.

Elle E., and Hare, J.D. 2002. Environmentally induced variation in floral traits affects the mating system in Datura wrightii. Funct. Ecol. 16: 79-88.

Endler, J.A. 1977. Geographic variation, speciation, and clines. Princeton Univ. Press, Princeton, New Jersey, USA.

Endler, J.A. 1995. Multiple trait coevolution and environmental gradients in guppies. Trends Ecol. Evol. 10: 22-29.

Esri, Inc. 2006. ArcGis 9.2. Website http://www.esri.com (accessed November 2008).

Etterson, J.R., Schneider, H.E., Soper Gorden, NL., and Weber, J.J. 2016. Evolutionary insights from studies of geographic variation: contemporary variation and looking to the future. Am. J. Bot. 103: 5-9. 
Falconer, D.S., and Mackay, T.F.C. 1996. Introduction to Quantiative Genetics. Longman, Harlow.

Fernández, J.D., Bosch, J., Nieto-Ariza, B., and Gómez, J.M. 2012. Pollen limitation in a narrow endemic plant: geographical variation and driving factors. Oecologia 170: 421-431.

Fishman, L., and Wyatt, R. 1999. Pollinator-mediated competition, reproductive character displacemement, and the evolution of selfing in Arenaria uniflora (Caryophyllaceae). Evolution 53: 1723-1733.

Fox, C.W., and Reed, D.H. 2011. Inbreeding depression increases with environmental stress: an experimental study and meta-analysis. Evolution 65: 246-258.

Frazee, J.E., and Marquis, R.J. 1994. Environmental contribution to floral trait variation in Chamaecrista fasciculate (Fabaceae, Caesalpinoideae). Am. J. Bot. 81: 206-215.

Garber, E.D. 1958. The genus Collinsia. VI. Distribution of pigments in the flowers. Bot. Gaz. 119: 240-243.

Gauzere, J., Oddou-Muratorio, S., Pichot, C., Lefèvre, F., and Klein, E. 2013. Biases in quantitative genetic analyses using open-pollinated progeny tests from natural tree populations. Acta Bot. Gallica 160: 225-236.

Goodwillie, C., Kalisz, S., and Eckert, C.G. 2005. The evolutionary enigma of mixed mating systems in plants: occurrence, theoretical explanations, and empirical evidence. Annu. Rev. Ecol. Evol. Syst. 36:.47-79.

Goodwillie, C., Sargent, R., Eckert, C.G., Elle, E., Geber, M.A., Johnston, M.O., Kalisz, S., Moeller, D.A., Ree, R.H., Vallejo-Marin, M., Winn, A.A. 2010. Correlated evolution of mating system and floral display traits in flowering plants and its implications for the distribution of mating system variation. New Phytol. 185: 311-321. 
Hansen, T.F., Pélabon, C., and Houle, D. 2011. Heritability is not evolvability. Evol. Biol. 38: 258-277.

Harder, L.D., Richards, S.A., and Routley, M.B. 2008. Effects of reproductive compensation, gamete discounting and reproductive assurance on mating-system diversity in hermaphrodites. Evolution 62: 157-172.

Hazzouri, K.M., Escobar, J.S., Ness, R.W., and Newman, L.K. 2013. Comparative population genomics in Collinsia sister species reveals evidence for reduced effective population size, relaxed selection and evolution of biased gene conversion with an ongoing mating system shift. Evolution 67: 1263-1278.

Herlihy, C.R., and Eckert, C.G. 2007. Evolutionary analysis of a key floral trait and its effect on the mating system in Aquilegia canadensis (Ranunculaceae). Evolution 61: 1661-1674.

Herrera, C.M. 1995. Floral biology, microclimate, and pollination by ectothermic bees in an early-blooming herb. Ecology 76: 218-228.

Herrera, C.M., Castellanos, M.C., and Medrano, M. 2006. Geographic context of floral evolution: toward an improved research programme in floral diversification. In Ecology and evolution of flowers. Edited by L.D. Harder, and S.C.H. Barrett. Oxford Univ. Press, Oxford, Great Britain. pp 278-294.

Hersh, E., Madjidian, J.A., Andersson, S., Strandh, M., Armbruster, W.S., and Lankinen, Å. 2015. Sexual antagonism in the pistil varies among populations of a hermaphroditic mixedmating plant. J. Evol. Biol. 28: 1321-1334.

Hijmans, R.J., Cameron, S.E., Parra, J.L., Jones, P.G., and Jarvis, A. 2005. Very high resolution interpolated climate surfaces for global land areas. Int. J. Climatol. 25:.19651978. 
Hodgins, K.A., and Barrett, S.C.H. 2008. Geographic variation in floral morphology and style-morph ratios in a sexually polymorphic daffodil. Am. J. Bot. 95: 185-195.

Holsinger, K.E. 1991. Mass-action models of plant mating systems: the evolutionary stability of mixed mating systems. Am. Nat. 138: 606-622.

Holtsford, T.P, and Ellstrand, N.C. 1992. Genetic and environmental variation in floral traits affecting outcrossing rate in Clarkia tembloriensis (Onagraceae). Evolution 46: 216-225.

Ivey, C.T., and Carr, D.E. 2012. Test for the joint evolution of mating system and drought escape in Mimulus. Ann. Bot. 109:.583-598.

Johnston, M.O., Porcher, E., Cheptou, P.-O., Eckert, C.G., Elle, E., Geber, M.A., Johnston, M.O., Kalisz, S., Kelly, J.K., Moeller, D.A., Vallejo-Marin, M., and Winn, A.A. 2009. Correlations among fertility components can maintain mixed mating in plants. Am. Nat. 173: $1-11$.

Jorgensen, R., and Arathi, H.S. 2013. Floral longevity and autonomous selfing are altered by pollination and water availability in Collinsia heterophylla. Ann. Bot. 112: 821-828.

Kalisz, S., Randle, A., Chaiffetz, D., Faigeles, M., Butera, A., and Beight, C. 2012. Dichogamy correlates with outcrossing rate and defines the selfing syndrome in the mixedmating genus Collinsia. Ann. Bot. 109:.571-582.

Kalisz, S., Vogler, D.W, and Hanley, K.M. 2004. Context-dependent autonomous selffertilization yields reproductive assurance and mixed mating. Nature 430: 884-887.

Kearns, C.A., and Inouye, D.W. 1993. Techniques for pollination biologists. Univ. Press of Colorado, Niwot, Colorado, USA.

Kelly, J.K., and Arathi, H.S. 2003. Inbreeding and the genetic variance in floral traits of Mimulus guttatus. Heredity 90: 77-83. 
Lande, R., and Arnold, S.J. 1983. The measurement of selection on correlated characters. Evolution 37: 1210-1226.

Lande, R., and Schemske, D.W. 1985. The evolution of self-fertilization and inbreeding depression in plants. I. Genetic models. Evolution 39: 24-40.

Lankinen, Å. 2009 Upper petal lip colour polymorphism in Collinsia heterophylla (Plantaginaceae): genetic basis within a population and its use as a genetic marker. J. Genet. 88: 205-215.

Lankinen, Å, and Kiboi, S. 2007. Pollen-donor identity affects timing of stigma receptivity in Collinsia heterophylla (Plantaginaceae): a sexual conflict during pollen competition? Am. Nat. 170: 854-863.

Lankinen, Å., Armbruster, W.S., and Antonsen, L. 2007. Delayed stigma receptivity in Collinsia heterophylla (Plantaginaceae): genetic variation and adaptive significance in relation to pollen competition, delayed self-pollination, and mating-system evolution. Am. J. Bot. 94: 1183-1192.

Lapointe, F.-J., and Rissler, L.J. 2005. Congruence, concensus, and the comparative phylogeography of codistributed species in California. Am. Nat. 166:.290-299.

Levin, D.A. 1972. Competition for pollinator service: a stimulus for the evolution of autogamy. Evolution 26: 668-669.

Levin, D.A. 2010. Environment-enhanced self-fertilization: implications for niche shifts in adjacent populations. J. Ecol. 98: 1276-1283.

Linhart, Y.B., and Grant, M.C. 1996. Evolutionary significance of local genetic differentiation in plants. Annu. Rev. Ecol. Evol. Syst. 27:.237-277.

Lloyd, D.G. 1979. Some reproductive factors affecting the selection of self-fertilisation in plants. Am. Nat. 113: 67-79. 
Maad. J., Armbruster, W.S., and Fenster, C.B. 2013. Floral size variation in Campanula rotundifolia (Campanulaceae) along altitudinal gradients: patterns and possible selective mechanisms. Nord. J. Bot. 31: 361-371.

Madjidian, J.A., and Lankinen, Å. 2009. Sexual conflict and sexually antagonistic coevolution in an annual plant. PLoS One 4: e5477.

Madjidian, J.A., Hydbom, S., and Lankinen, Å. 2012a. Influence of number of pollinations and pollen load size on maternal fitness costs in Collinsia heterophylla: implications for existence of a sexual conflict over timing of stigma receptivity. J. Evol. Biol. 25:.16231635.

Madjidian, J.A., Andersson, S., and Lankinen, Å. 2012b. Estimation of heritability, evolvability and genetic correlations of two pollen and pistil traits involved in a sexual conflict over timing of stigma receptivity in Collinsia heterophylla (Plantaginaceae). Ann. Bot. 110: 91-99.

Mal, T.K., and Lovett-Doust, J. 2005. Phenotypic plasticity in vegetative and reproductive traits in an invasive weed, Lythrum salicaria (Lythraceae), in response to soil moisture. Am. J. Bot. 92: 819-825.

Mazer, S.J., Paz, H., and Bell, M.D. 2004. Life history, floral development, and mating system in Clarkia xantiana (Onagraceae): do floral and whole-plant rates of development evolve independently? Am. J. Bot. 91: 2041-2050.

McCall, C., and Primack, R.B. 1992. Influence of flower and characteristics, weather, time of day, and season on insect visitation rates in three plant communities. Am. J. Bot. 79: 434442.

Murren, C.J., Auld, J.R., Callahan, H., Ghalambor, C.K., Handelsman, C.A., Heskel, M.A., Kingsolver, J.G., Maclean, H.J., Masel, J., Maughan, H., Pfennig, D.W., Relyea, R.A., 
Seiter, S., Snell-Rood, E., Steiner, U.K., and Schlichting, C.D. 2015. Constraints on the evolution of phenotypic plasticity: limits and costs of phenotype and plasticity. Heredity 115: 293-301.

Neese, E.C. 1993. Collinsia. In The Jepson manual: higher plants of California. Edited by J.C. Hickman. Univ. of California Press, Berkeley, California, USA. pp 1024-1027.

Newsom, V.M. 1929. A revision of the genus Collinsia. Bot. Gaz. 87: 260-231.

Pérez, F., León, C., and Muñoz, T. 2013. How variable is delayed selfing in a fluctuating pollinator environment? A comparison between a delayed selfing and a pollinatordependent Schizanthus species of the high Andes. Evol. Ecol. 27: 911-922.

Peterson, M. L., and Kay, K. M. 2014. Mating system plasticity promotes persistence and adaptation of colonizing populations of hermaphroditic angiosperms. Am. Nat. 185: 28-43.

Price, T.D., Qvarnström, A., and Irwin, D.E. 2003. The role of phenotypic plasticity in driving genetic evolution. Proc. R. Soc. Lond. B 270: 1433-1440.

Porcher, E, and Lande, R. 2005. Reproductive compensation in the evolution of plant mating systems. New Phytol. 166: 673-684.

Potts, S.G., Vulliamy, B., Roberts, S., O’Toole, C., Dafni, A., Ne’Eman, G., and Willmer, P. 2005. Role of nesting resources in organising diverse bee communities in a Mediterranean landscape. Ecol. Entomol. 30:.78-85.

R Developmental Core Team, 2014. R: a language and environment for statistical computing version 3.1.1. R Foundation for Statistical Computing Vienna, Austria. ISBN 3-900051-070, website http://www.R-project.org/.

Randle, A.M., Slyder, J.B., and Kalisz, S. 2009. Can differences in autonomous selfing ability explain range size among sister-taxa pairs of Collinsia (Plantaginaceae)? An extension of Baker's Law. New Phytol. 183:.618-629. 
Runions, C.J., and Geber, M.A. 2000. Evolution of the self-pollinating flower in Clarkia xantiana (Onagraceae). I. Size and development of floral organs. Am. J. Bot. 87:.14391451.

Schlichting, C.D., and Pigliucci, M. 1998. Phentypic evolution: a reaction norm perspective. Sinauer Associates, Inc., Sunderland, Massachusetts.

Slotte, T., Hazzouri, K.M., Ågren, J.A., Koenig, D., Maumus, F., Guo, Y.-L., Steige, K., Escobar, J.S., Newman, L.K., Wang, W., Mandákova, T., Vello, E., Smith, L.M., Henz, S.R., Steffen, J., Takuno, S., Brandvain, Y., Coop, G., Andolfatto, P., Hu, T.T., Blanchette, M., Clark, R.M., Quesneville, H., Nordborg, M., Gaut, B.S., Lysak, M.A., Jenkins, J., Grimwood, J., Chapman, J., Prochnik, S., Shu, S., Rokhsar, D., Schmutz, J., Weigel, D., and Wright S.I. 2013. The Capsella rubella genome and the genomic consequences of rapid mating system evolution. Nature Genet. 45:.831-835.

Sokal, R.R., and Rohlf, F.J. 1995. Biometry, 3rd edn. WH Freeman \& Co, New York.

Spigler, R.B., and Kalisz, S. 2013. Phenotypic plasticity in mating-system traits in the annual Collinsia verna. Botany 91: 597-604.

SPSS, 2011. IBM Corp. Released 2011 IBM SPSS Statistics for Windows, Version 20.0. Armonk, NY: IBM Corp.

Squillace. A.E. 1974. Average genetic correlations among offspring from open-pollinated forest trees. Silvae Genet. 23:.149-156.

Statistica. 2005. STATISTICA 7.1. Statsoft Inc., Chicago, Illinois, USA.

Stebbins, G.L. 1950. Variation and evolution in plants. Columbia Univ Press, New York, USA.

Stebbins, G.L. 1974. Flowering plants: evolution above the species level. Harvard Univ. Press, Cambridge, Massachusetts, USA. 
Stock, A.J., Campitelli, B.E., and Stinchcombe, J.R. 2014. Quantitative genetic variance and multiple clines in the Ivyleaf morning glory, Ipomoea hederacea. Phil. Trans. R. Soc. B. 369: 20130259.

Strauss SY, JB Whittall 2006 Non-pollinator agents of selection on floral traits. In Ecology and evolution of flowers. Edited by L.D. Harder, and S.C.H. Barrett. Oxford Univ. Press, Oxford, Great Britain. pp. 120-138.

Teixido, A.L., and Valladares, F. 2013. Large and abundant flowers increase indirect costs of corollas: a study of coflowering sympatric Mediterranean species of contrasting flower size. Oecologia 173:.73-81.

Thomann, M., Imbert, E., Devaux, C., and Cheptou, P.-O. 2013. Flowering plants under global pollinator decline. Trends Plant Sci. 18:.353-359.

Torres-Diaz, C., Cavieres, L.A., Munoz-Ramirez, C., and Arroyo, M.T.K. 2007. Consequences of microclimate variation on insect pollinator visitation in two species of Chaetanthera (Asteraceae) in the central Chilean Andes. Rev. Chil. Hist. Nat. 80: 455-468. Totland, O., and Schulte-Herbrüggen, B. 2003. Breeding system, insect flower visitation, and floral traits of two alpine Cerastium species in Norway. Arct. Antarct. Alp. Res. 35:.242247.

Vallejo-Martín, M., and Barrett, S.C.H. 2009. Modification of flower architecture during early stages in the evolution of self-fertilization. Ann. Bot. 103: 951-962.

van Etten, M.L., and Brunet, J. 2013. The impact of global warming on floral traits that affect the selfing rate in a high-altitude plant. Int. J. Plant Sci. 174: 1099-1108.

van Kleunen, M., and Fisher, M. 2005. Constraints on the evolution of adaptive phenotypic plasticity in plants. New Phytol. 166: 49-60. 
Weil, J. and Allard, R.W. 1964. The mating system and genetic variability in natural populations of Collinsia heterophylla. Evolution 18:515-525.

West-Eberhard, M.J. 2005. Developmental plasticity and the origin of species differences. Proc. Natl. Acad. Sci U.S.A. 102: 6453-645.

Wiens, J.J., Ackerly, D.D., Allen, A.P., Anacker, B.L., Buckley, L.B., Cornell, H.V., Damschen, E.I., Davies, T.J., Grytnes, J.-A., Harrison, S.P., Hawkins, B.A., Holt, R.D., McCain, C.M., and Stephens, P.R. 2010. Niche conservatism as an emerging principle in ecology and conservation biology. Ecol. Lett. 13: 1310-1324.

Winn, A.A., Elle, E., Kalisz, S., Cheptou, P.-O., Eckert, C.G., Goodwillie, C., Johnston, M.O., Moeller, D.A., Ree, R.H., Sargent, R.D., and Vallejo-Marin, M. 2011. Analysis of inbreeding depression in mixed-mating plants provide evidence for selective interference and stable mixed mating. Evolution 65: 3339-3359.

Wright, S.I., Kalisz, S., and Slotte, T. 2013. Evolutionary consequences of self-fertilization in plants. Proc. R. Soc. Lond. Biol. 280: 20130133. 
Table 1. General linear models (analyses of variance and nested analyses of variance) for field- and greenhouse-measured floral traits for Collinsia heterophylla populations originating from four regions in California, USA.

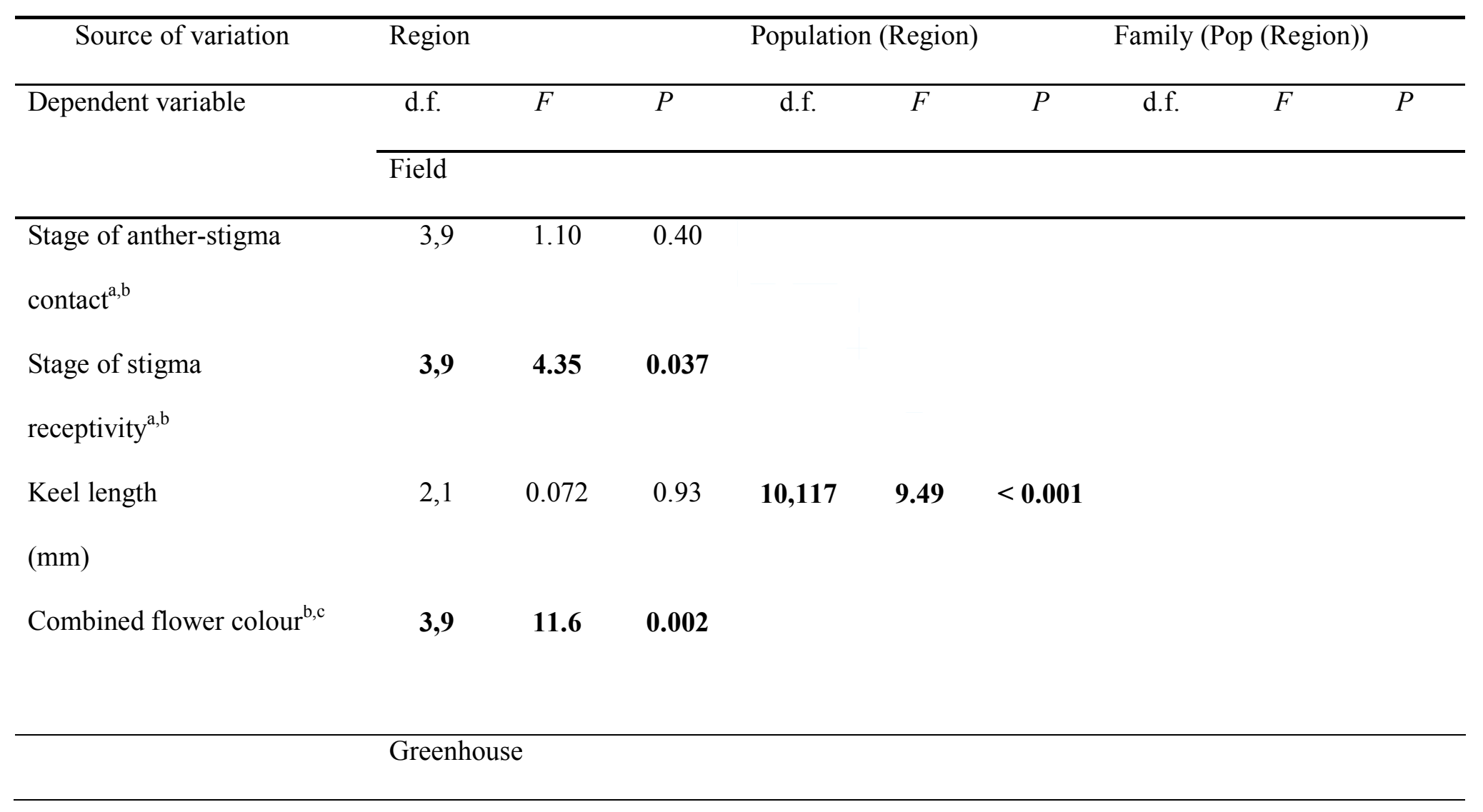




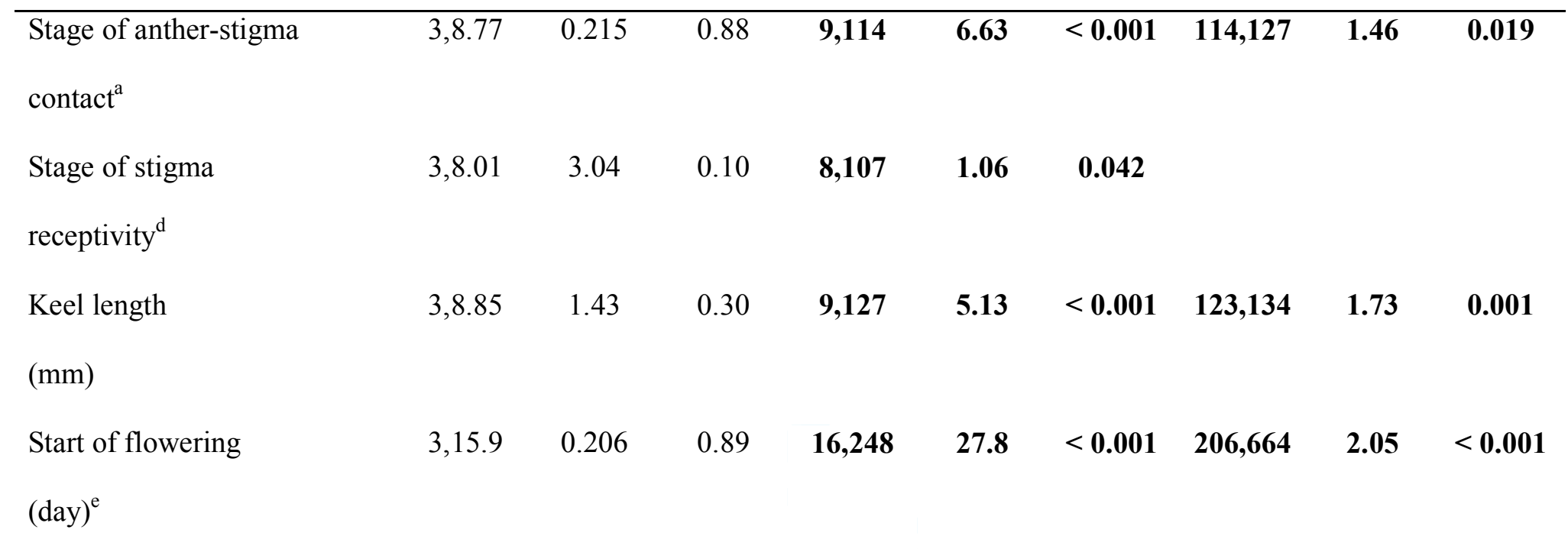

Note: Population is nested within region and family within population and region. Population was taken into account when estimates within populations were based on plant individuals. d.f. denotes the numerator and denominator degrees of freedom, respectively.

${ }^{\text {a Stage }} 0=$ day of flower opening, stage 1-4 equals the number of dehisced anthers (approx. one per day).

${ }^{\mathrm{b}}$ Analysis based on population means.

${ }^{\mathrm{c}}$ Representing corolla colour and morph proportion on upper lip.

${ }^{\mathrm{d}}$ Stage $0=$ day of flower opening, stage 1-4 estimated as day after flower opening.

${ }^{\mathrm{e}}$ Estimated as day after first flowering plant. 
Table 2. Estimates of among- and within-family variance $\left(V_{\text {Family }}\right.$ and $\left.V_{\text {Error }}\right)$,"broad-sense" heritability $\left(H^{2}\right)$ and heritability adjusted for the range of recorded selfing rates (Adjusted $H^{2}$ ), for floral traits measured on greenhouse-grown plants of Collinsia heterophylla.

\begin{tabular}{lccc}
\hline & $\begin{array}{c}\text { Stage of anther-stigma } \\
\text { contact }^{\mathrm{a}}\end{array}$ & $\begin{array}{c}\text { Keel length } \\
\text { Parameter }\end{array}$ & $\begin{array}{c}\text { Start of flowering } \\
(\text { day })^{\mathrm{b}}\end{array}$ \\
\hline$V_{\text {Family }}$ & 0.044 & 0.689 & 6.08 \\
$V_{\text {Error }}$ & 0.193 & 1.86 & 22.3 \\
$H^{2}$ & 0.743 & 1.08 & 0.857 \\
Adjusted $H^{2}$ & $0.333-0.544$ & $0.483-0.790$ & $0.384-0.627$ \\
$n^{\mathrm{c}}$ & 13 & 13 & 20 \\
\hline
\end{tabular}

Note: $H^{2}$ calculated as $H^{2}=V_{G} / V_{P}$ where $V_{G}$ (genetic variance) $=4 V_{\text {Family }}$ and $V_{P}$ is the total phenotypic variance within populations $\left(V_{\text {Family }}+V_{\text {Error }}\right)$; Adjusted $H^{2}$ refers to estimates adjusted for the highest and lowest selfing rate recorded for our study populations in a parallel study, see methods for details.

${ }^{\text {a }}$ Stage $0=$ day of flower opening, stage 1-4 equals the number of dehisced anthers (approx. one per day).

${ }^{\mathrm{b}}$ Estimated as day after first flowering plant.

${ }^{c}$ Number of populations. 
Table 3. Family-mean correlations between floral traits measured in greenhouse-grown maternal families of Collinsia heterophylla populations, indicated by Pearson $r$.

\begin{tabular}{|c|c|c|c|c|c|c|c|c|c|}
\hline \multirow[t]{2}{*}{ Correlated traits } & \multicolumn{3}{|c|}{$\begin{array}{c}\text { Stage of stigma } \\
\text { receptivity }^{\mathrm{b}}\end{array}$} & \multicolumn{3}{|c|}{$\begin{array}{c}\text { Keel length } \\
(\mathrm{mm})\end{array}$} & \multicolumn{3}{|c|}{ 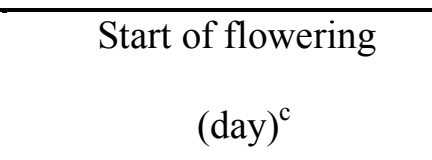 } \\
\hline & $r$ & d.f. & $P$ & $\bar{r}$ & d.f. & $P$ & $r$ & d.f. & $P$ \\
\hline $\begin{array}{l}\text { Stage of anther-stigma } \\
\text { contact }^{\mathrm{b}}\end{array}$ & 0.183 & 115 & 0.049 & 0.218 & 167 & 0.004 & 0.147 & 164 & 0.059 \\
\hline $\begin{array}{l}\text { Stage of stigma } \\
\text { receptivity }\end{array}$ & & & & 0.038 & 119 & 0.680 & -0.168 & 117 & 0.067 \\
\hline $\begin{array}{l}\text { Keel length } \\
(\mathrm{mm})\end{array}$ & & & & & & & 0.008 & 168 & 0.920 \\
\hline
\end{tabular}

Note: Analyses controlled for differences between population means by performing all correlations on standardized residuals.

${ }^{\text {a }}$ Stage $0=$ day of flower opening, stage 1-4 equals the number of dehisced anthers (approx. one per day). 


\section{Botany}

Page 46 of 55

46

${ }^{\mathrm{b}}$ Stage $0=$ day of flower opening, stage 1-4 estimated as day after flower opening.

${ }^{\mathrm{c}}$ Estimated as day after first flowering plant. 
Fig. 1. Field-estimated geographic variation of four floral traits across populations of Collinsia heterophylla in four regions of California, USA. Region numbers shown in circles. Grey contours represent contours of mountain ranges and black areas represent urban areas. Overview USA map shows California (red) and the study region (rectangle). (a) Stage of anther-stigma contact, (b) stage of stigma receptivity (stage of floral development), and keel length $(\mathrm{mm})$ in 13 populations. Stage $0=$ day of flower opening, stage 1-4 equals the number of dehisced anthers (approx. one per day). (d) Corolla colour (light to dark purple, the triangle with a dot represents an intermediate colour) and (e) percentage of white-lipped and purplelipped plants (indicated by white and dark colour, respectively) in 24 populations (including two early-flowering ones scored in 2003). Maps created in ArcGIS using data from DCW (http://data.geocomm.com/readme/dcw/dcw.html) and this study.

Fig. 2. Field-estimated measures of stage of floral development across 13 populations of Collinsia heterophylla in four regions of California, USA, and their relation to climate or site characteristics. (a) Stage of anther-stigma contact increased with higher annual mean temperature $(b=0.343 \pm 0.094$ (s.e.), d.f. $=11, P=0.004)$. (b) Standardized residuals (to control for region and spatial autocorrelation) of stage of stigma receptivity decreased with the percentage of ground covered by vegetation $(b=-0.616 \pm 0.184$, d.f. $=11, P=0.006)$. Stage $0=$ day of flower opening, stage 1-4 equals the number of dehisced anthers (approx. one per day).

Fig. 3. Comparison of population means for (a) Stage of anther-stigma contact, (b) stage of stigma receptivity and (c) keel length estimated in the field vs. in greenhouse-grown plants of Collinsia heterophylla.. $r=$ correlation coefficient. 


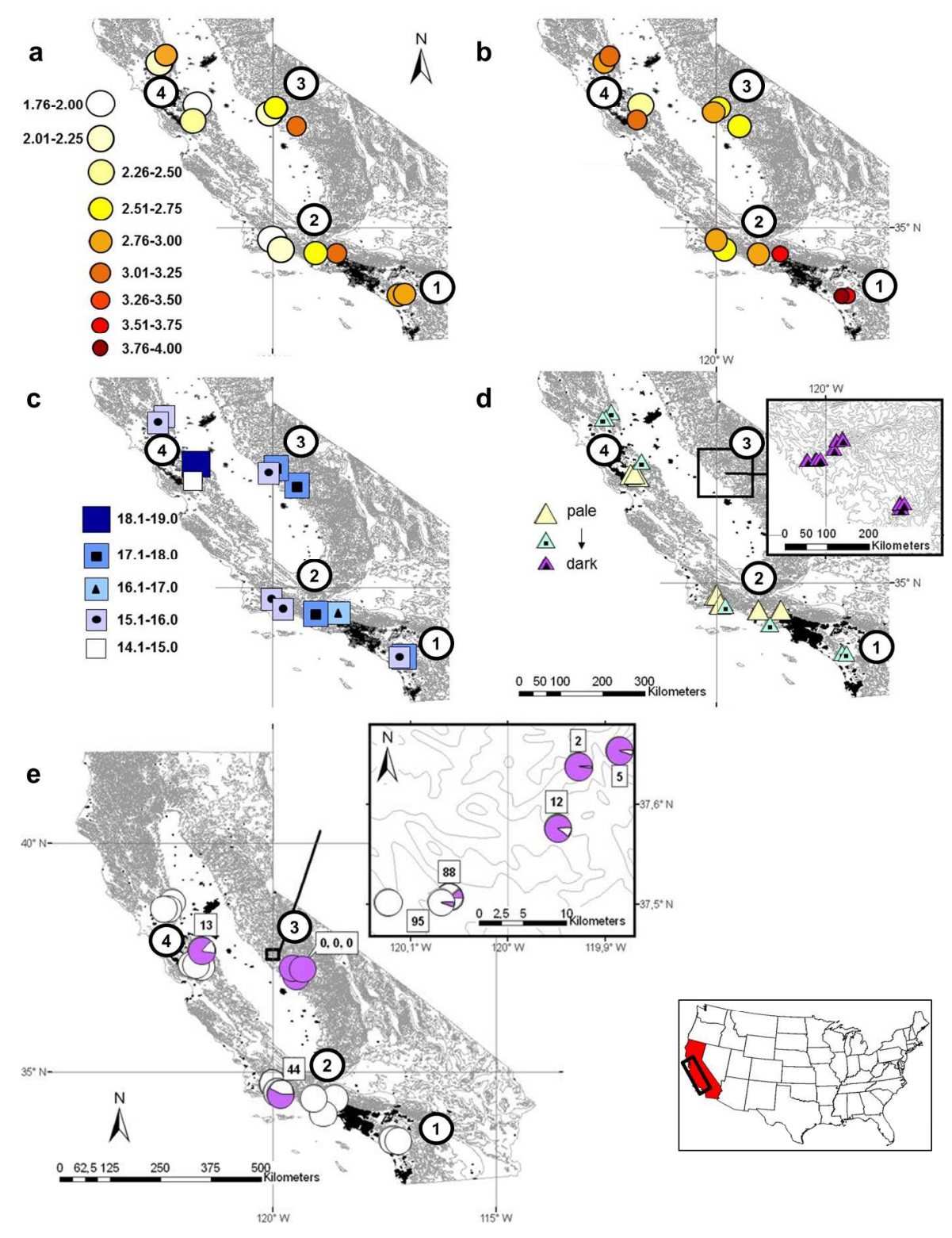

$254 \times 338 \mathrm{~mm}(300 \times 300$ DPI $)$ 

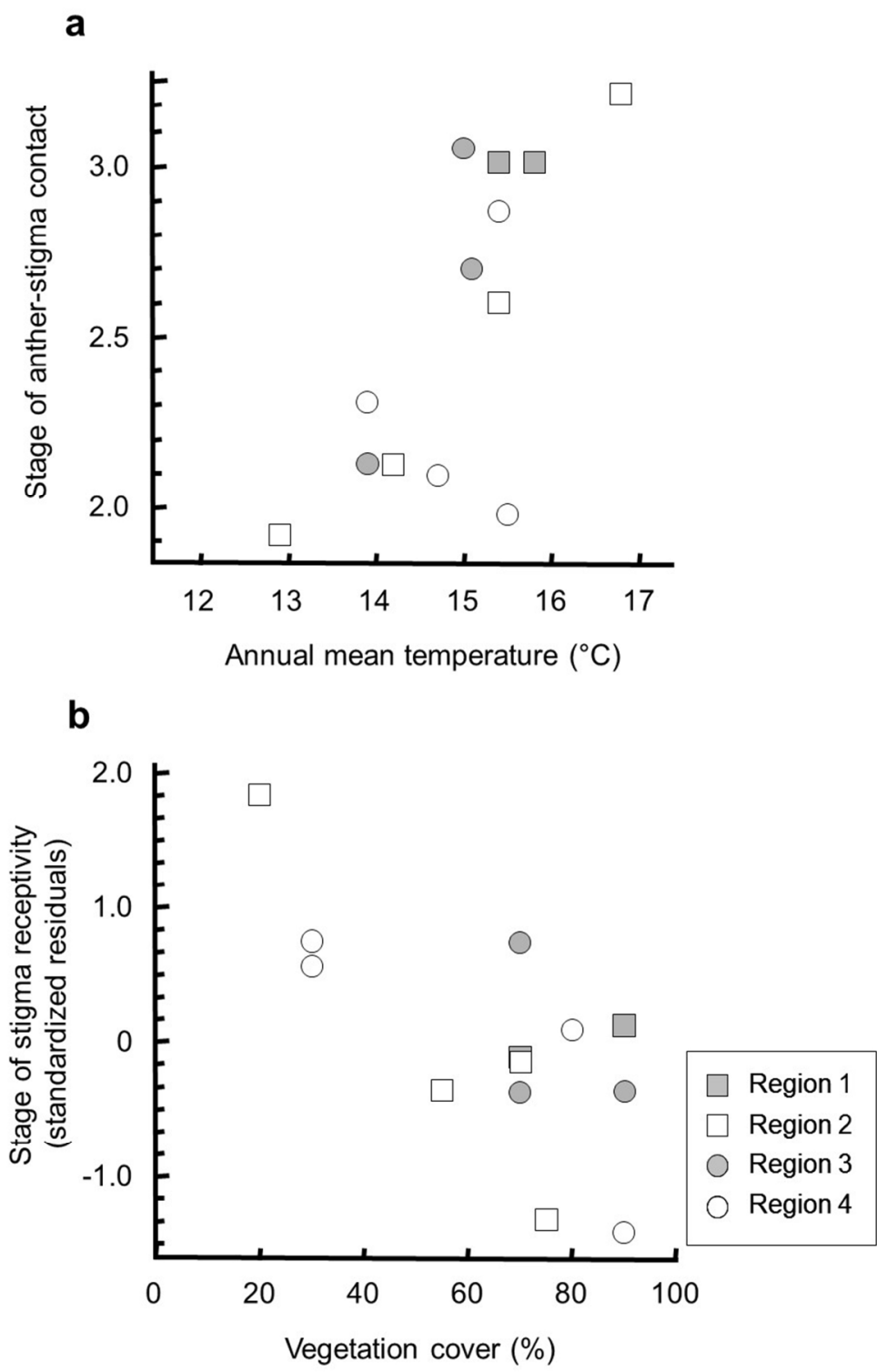

$254 \times 338 \mathrm{~mm}(300 \times 300 \mathrm{DPI})$ 
a

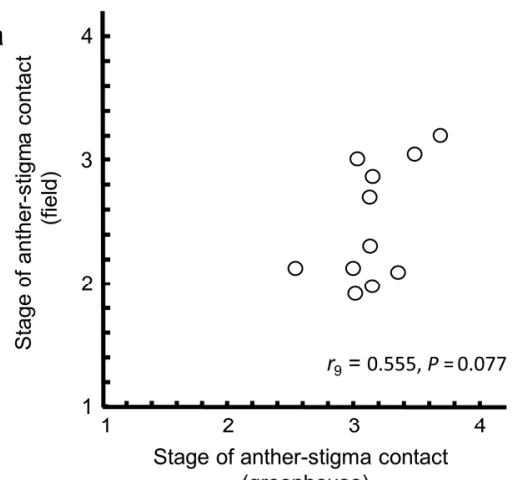

c

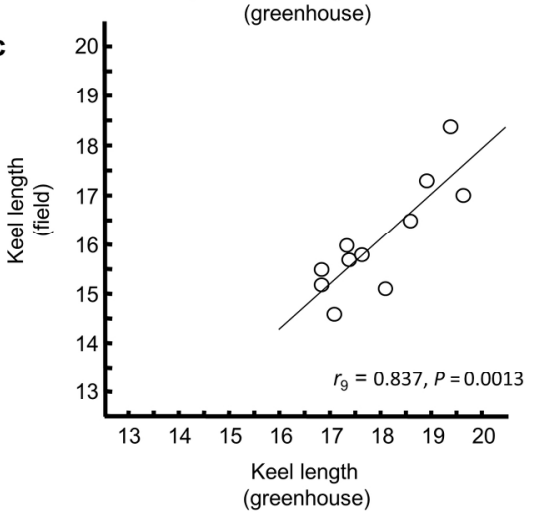

$b$

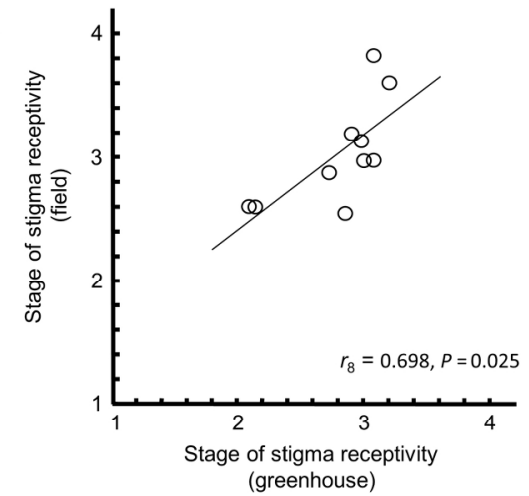

$190 \times 142 \mathrm{~mm}(300 \times 300 \mathrm{DPI})$ 
Table A1. Locations of populations of Collinsia heterophylla in California, USA, included in the field (F) and greenhouse (G) study.

\begin{tabular}{|c|c|c|c|c|c|c|}
\hline Population & Region & County & Latitude & Longitude & Study & $N$ heritability $^{\mathrm{a}}$ \\
\hline 2 & 1 & Riverside & $33.51807 \mathrm{~N}$ & $117.30454 \mathrm{~W}$ & $\mathrm{~F}^{\mathrm{b}}$ & \\
\hline 3 & 1 & Riverside & $33.51655 \mathrm{~N}$ & $117.33807 \mathrm{~W}$ & $F^{b}, G^{b}$ & 14,$28 ; 14,28 ; 17,78$ \\
\hline 1 & 2 & Los Angeles & $34.43155 \mathrm{~N}$ & $118.62989 \mathrm{~W}$ & $F^{b}, G^{b}$ & 13,$26 ; 13,26 ; 17,68$ \\
\hline 4 & 2 & Ventura & $34.42650 \mathrm{~N}$ & $119.10570 \mathrm{~W}$ & $\mathrm{~F}^{\mathrm{b}}$ & \\
\hline 202 & 2 & Ventura & $34.12175 \mathrm{~N}$ & $118.87294 \mathrm{~W}$ & F, G & $-;-; 8,25$ \\
\hline 5 & 2 & Santa Barbara & $34.52394 \mathrm{~N}$ & $119.83353 \mathrm{~W}$ & $\mathrm{~F}^{\mathrm{b}}, \mathrm{G}^{\mathrm{b}}$ & 3,$6 ; 3,6 ; 3,10$ \\
\hline 7 & 2 & Santa Barbara & $34.74107 \mathrm{~N}$ & $120.01358 \mathrm{~W}$ & $F^{b}, G^{b}$ & 14,$28 ; 14,28 ; 12,45$ \\
\hline 61 & 2 & Santa Barbara & $34.56150 \mathrm{~N}$ & $119.92507 \mathrm{~W}$ & $\mathrm{~F}, \mathrm{G}^{\mathrm{b}}$ & 15,$30 ; 15,30 ; 19,90$ \\
\hline 72 & 2 & Santa Barbara & $34.73921 \mathrm{~N}$ & $120.06352 \mathrm{~W}$ & G & - ; - ; 15,50 \\
\hline
\end{tabular}




\begin{tabular}{|c|c|c|c|c|c|c|}
\hline 10 & 3 & Mariposa & $37.57681 \mathrm{~N}$ & $119.94864 \mathrm{~W}$ & $F^{b}, G^{b}$ & 9,$18 ; 9,18 ; 12,47$ \\
\hline 11 & 3 & Mariposa & $37.50232 \mathrm{~N}$ & $120.06873 \mathrm{~W}$ & $F^{b}, G^{b}$ & 10,$18 ; 10,18 ; 15,72$ \\
\hline 91 & 3 & Mariposa & $37.63884 \mathrm{~N}$ & $119.92843 \mathrm{~W}$ & $\mathrm{~F}, \mathrm{G}$ & - ; - ; 2,6 \\
\hline 112 & 3 & Mariposa & $37.50751 \mathrm{~N}$ & $120.06113 \mathrm{~W}$ & $\mathrm{~F}$ & \\
\hline 203 & 3 & Mariposa & $37.65482 \mathrm{~N}$ & $119.88640 \mathrm{~W}$ & G & - ; - ; 15,49 \\
\hline 204 & 3 & Mariposa & $37.50196 \mathrm{~N}$ & $120.12360 \mathrm{~W}$ & $\mathrm{G}$ & - ; - ; 10,46 \\
\hline 13 & 3 & Madera & $37.17936 \mathrm{~N}$ & $119.51235 \mathrm{~W}$ & $\mathrm{~F}^{\mathrm{b}}, \mathrm{G}^{\mathrm{b}}$ & 9,$18 ; 9,18 ; 10,33$ \\
\hline 121 & 3 & Madera & $37.21785 \mathrm{~N}$ & $119.50706 \mathrm{~W}$ & $\mathrm{~F}$ & \\
\hline 122 & 3 & Madera & $37.20747 \mathrm{~N}$ & $119.50018 \mathrm{~W}$ & $\mathrm{~F}$ & \\
\hline 8 & 4 & Alameda & $37.65077 \mathrm{~N}$ & $121.60250 \mathrm{~W}$ & $\mathrm{~F}^{\mathrm{b}}, \mathrm{G}^{\mathrm{b}}$ & 2,$4 ; 2,4 ; 3,9$ \\
\hline 14 & 4 & Napa & $38.58764 \mathrm{~N}$ & $122.37461 \mathrm{~W}$ & $\mathrm{~F}^{\mathrm{b}}$ & \\
\hline 17 & 4 & Napa & $38.72380 \mathrm{~N}$ & $122.26601 \mathrm{~W}$ & $F^{b}, G^{b}$ & 7,$14 ; 7,14 ; 9,31$ \\
\hline
\end{tabular}




\begin{tabular}{ccccccc}
\hline 142 & 4 & Napa & $38.58450 \mathrm{~N}$ & $122.37328 \mathrm{~W}$ & $\mathrm{~F}, \mathrm{G}^{\mathrm{b}}$ & 9,$18 ; 9,18 ; 11,42$ \\
151 & 4 & Napa & $38.64407 \mathrm{~N}$ & $122.37349 \mathrm{~W}$ & $\mathrm{G}^{\mathrm{b}}$ & 14,$28 ; 22,44 ; 19,79$ \\
161 & 4 & Napa & $38.70233 \mathrm{~N}$ & $122.43417 \mathrm{~W}$ & $\mathrm{G}$ & $-;-; 9,32$ \\
19 & 4 & Santa Clara & $37.32918 \mathrm{~N}$ & $121.68127 \mathrm{~W}$ & $\mathrm{~F}^{\mathrm{b}}, \mathrm{G}^{\mathrm{b}}$ & 8,$16 ; 8,16 ; 12,40$ \\
181 & 4 & Santa Clara & $37.36280 \mathrm{~N}$ & $121.75520 \mathrm{~W}$ & $\mathrm{~F}, \mathrm{G}$ & $-;-; 7,18$ \\
& & & & &
\end{tabular}

${ }^{\mathrm{a}} N=$ number of maternal families, number of plants for stage of anther-stigma contact, keel length and start of flowering, respectively.

${ }^{\mathrm{b}}$ All floral traits measured.

Table A2. Trait loadings for 12 floral traits on the first principal components (PCs 1-3) in a PCA based on a Pearson correlation coefficient matrix calculated from field-estimated means for 13 populations of Collinsia heterophylla. Values in parentheses denote the percentage of variance explained by each component.

\begin{tabular}{lccc}
\hline Floral trait & PC 1 (41.0\%) & PC 2 (21.0\%) & PC 3 (18.4 \%) \\
\hline Stage of anther-stigma contact $^{\mathrm{a}}$ & & & \\
\hline
\end{tabular}


Rate of onset of anther-stigma contact ${ }^{\mathrm{b}}$

Stage of full stigma receptivity ${ }^{\mathrm{a}}$

Rate of onset of full stigma receptivity ${ }^{\mathrm{b}}$

Stage of partial of stigma receptivity

Rate of onset of partial of stigma receptivity ${ }^{b}$

Stage of full - partial stigma receptivity ${ }^{\mathrm{a}}$

Corolla colour

Proportion of the white-lipped morph ${ }^{c}$

Keel length (mm)

Banner height (mm)

Corolla tube length (mm)
0.550

0.901

0.779

0.873

0.901

0.863

$-0.185$

0.523

0.145

$-0.184$

0.100
$-0.658$

0.246

0.003

0.225

$-0.111$

0.250

$-0.906$

$-0.070$

0.695

0.203

0.870

0.697

0.541

$-0.014$

0.911

${ }^{\mathrm{a}}$ Stage $0=$ day of flower opening, stage 1-4 equals the number of dehisced anthers (approx. one per day). 
${ }^{b}$ Log-transformed

${ }^{\mathrm{c}}$ Arcsine-square-root transformed 